\title{
miscellany
}

\section{DARE: the Drug-Induced Arrhythmia Risk Evaluation Study}

Ventricular arrhythmias owing to psychiatric and other drugs can cause lifethreatening events that are usually a result of prolongation of cardiac repolarisation, torsades de pointes and ventricular fibrillation. These events have generated public and medical concern because of their unpredictability and the lack of understanding of their epidemiological and clinical significance. Drugs such as thioridazine and droperidol have been withdrawn from the market because of this side-effect.

The Dare study is a collaboration between St George's Hospital (London) and the Drug Safety Research Unit (DSRU; Southampton), funded by the British Heart Foundation. The lead researchers are Professors A. J. Camm and S. A. Shakir. The study was launched officially on 1 July 2003 and will run for 5 years.

The study's principal aims and components are: (a) an epidemiological study to systematically document and follow-up incident cases in England, comparing them with controls - the relative risk of predisposing clinical factors will be calculated and both epidemiological cohorts will be described and the outcomes compared; (b) a genetic study to analyse blood samples from cases and controls for mutations and polymorphisms of the cardiac sodium and potassium ion channel genes implicated in the long QT and Brugada syndromes. We hypothesise that there is a significant association of genotype with drug-induced arrhythmia.

We expect that awareness of the condition and its predictability will thus be increased and result in safer prescribing and drug development.

The study will rely on recruiting patients (cases) who have had a proarrhythmic event via psychiatrists and hospital physicians in England. Inclusion criteria, diagnosed as secondary to therapeutic drug administration or drug overdose, will be at least one of the following:

- Documented torsades de pointes, ventricular fibrillation, or nonpolymorphic ventricular tachycardia

- Exacerbation of a pre-existing ventricular arrhythmia

- Severe drug-induced QT prolongation (QTc interval $\geqslant 500 \mathrm{~ms}$ )

- Moderate drug-induced QT prolongation (QTc interval $\geqslant 450 \mathrm{~ms}$ (male) or $\geqslant 470 \mathrm{~ms}$ (female)) and a clinical history of syncope or presyncope.

An information pack will be provided to all psychiatrists interested in participating in this study. The pack will include 'consent to contact cards' for both the patient and psychiatrist to briefly complete and return to the DSRU. This is all that will be required and we will address any local research ethics committee issues that may arise. If the patient permits contact to be made then a research nurse will arrange to visit them at home to discuss the study further and obtain consent. A questionnaire will be completed and electrocardiography performed, and a blood sample taken if the patient consents. The patient will also be asked to separately consent to access to their hospital and general practice medical notes.

We would be delighted to provide further details to interested health professionals, and are keen to visit any interested units in order to make a brief presentation. Please contact us on (023) 8040 6815, dare@dsru.org, or via http:// www.dsru.org for further details or if you feel that you may have a patient meeting the inclusion criteria.

\section{forthcoming events}

\section{The Committee on Publication}

Ethics Seminar 2006 will take place on Friday 10 March 2006 at BMA House, London. This year's seminar takes an international perspective and addresses publication ethics and research in several European countries and beyond, with interactive workshops on common ethical and editorial dilemmas. The manipulation of impact factors, and whether it is unethical, will also be considered. The seminar is for editors, authors and all those interested in increasing the standard of publication ethics. The event is free for COPE members and $£ 30.00$ plus VAT for non-members. For registrations or further information please contact the COPE Secretary at cope@bmjgroup.com or call 02073836602.

\section{Feeling Used? Making Service User} Involvement Real is the title of the Mind annual conference and exhibition 2006. At this conference an array of people with an interest in mental health services, including users, professionals and academics, will meet to share their experiences, both positive and negative, of service user involvement. The event will take place on 15-16 March 2006 at the Harrogate International Centre. For further details please call 0844-448 4450 or visit Mind's website at http:// www.mind.org.uk.
The British Psychoanalytical Society would like to announce Freud in the 21st Century - The Organic and Inner World, a conference taking place on Saturday 13 May 2006 at The Institute of Psychoanalysis. This conference will consider the relevance of Freud to modern-day psychiatry within the context of child, adult and old age psychiatry. The f75 fee includes lunch and drinks. A limited number of bursaries are available on application (the deadline for applications is 8 May 2006). For an application form please contact Winnie Dehaney, The Institute of Psychoanalysis, 112a Shirland Road, London W9 2EQ (tel: 020 7563 5016, e-mail:Winnie.Dehaney@ iopa.org.uk). See http://www. psychoanalysis.org.uk/events.htm for further information.

Midland Course In Group Work With Children And Adolescents 2006 is for all professionals who are interested in group work with children and adolescents. The course (non-residential) will be held at St Andrew's Hospital, Northampton over three weekends: 10-11 June 2006, 17-18 June 2006 and 2-3 July 2006. The course fee is $f 415$. For further information and application forms please contact Dr Kedar Dwivedi, Course Director, via sadrani@ntlworld.com or c/o 1 Becket Way, Northampton NN3 6EX.

\section{The First National ECT Nurse Training} Conference 2006 will take place on 6 September 2006 at The Conference Centre, Hull. This 1-day event for electroconvulsive therapy (ECT) clinic nurses has been organised by the National Association of Lead Nurses in ECT (NALNECT) and sponsored by Humber Mental Health Teaching NHS Trust and Dantec Electronics. The conference will provide updated information on ECT for nurses. Among the several eminent ECT speakers will be Dr Richard Barnes, Linda Cullen, a representative of the ECT accreditation service and members of the NALNECT committee. The $f 70$ fee includes lunch and a delegate pack. Places are limited and booking is essential. Closing date for applications is 26 July 2006. For further information contact Stephen Finch (tel: 01204 390758, e-mail: steve.finch@rbh.nhs. uk).

The International Early Psychosis Association (IEPA) conference, Beyond the Crossroads will take place on 3-6 October 2006 at the International Convention Centre in Birmingham. For further information please contact the event organisers, Happenings Australia (tel: +61 39866 6288, fax: +61 39866 6313, e-mail: event@happenings.com.au, website: http://www.happenings.com. $\mathrm{au})$. 